International Journal of Instruction e-ISSN: 1308-1470 • www.e-iji.net

Article submission code: 20201205174339

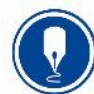

January $2022 \bullet$ Vol.15, No.1

p-ISSN: 1694-609X

pp. 401-420

Received: 05/12/2020

Revision: 02/07/2021
Accepted: 26/07/2021

OnlineFirst: 29/10/2021

\title{
Contemporary Perspective on Cognitive Development: Reconceptualising Situational Context as Embedded Model
}

Bilal Khalid Khalaf

Dr., Department of cultural relations, University of Anbar, Iraq, bk1142015@ gmail.com

\section{Zuhana Mohamed Zin}

Dr., Language Academy, UTM, Malaysia, zuhana.kl@utm.my

\section{Linda S. Al-Abbas}

Dr., Faculty of Arts \& Sciences, Middle East University, Jordan, lalabbas@meu.edu.jo

Educational societies encountered rapid development in all fields of knowledge, assisted by the invention of new technologies and development of linguistic systems. Over time, researchers contribute to design well known instructional models such as traditional-based and inquiry-based models. However, the previous literature investigations showed that most of the instructional models run into some limitations and challenges in the context of learning, whereas, traditional-based and inquiry-based were the dominant figures. The present study invested in exploring the process of translation concerning the cognitive challenges which translators encounter during translation activity. It contributes to develop an embedded situational context model for enhancing translators' cognitive performance through deploying four functional concepts from translation approach in systemic functional linguistics. A mixed-method approach is implemented by conducting thinking aloud experiment operated by two translation task and followed with retrospective interview to attain this goal. Conversely, a questionnaire on selfconfidence and participants' translations are used for the quantitative evaluations. Consequently, the shortcomings associated with the cognitive process of translation were surmounted. Thus, the functional concepts of the developed embedded model were incorporated to build, enhance, and validate background knowledge and cognitive skills of translators during translation activity toward professional translation practice.

Keywords: systematic functional linguistic, cognition, context, short-term memory, long-term memory

\section{Abbreviations and Samples:}

- TAP - Thinking aloud protocol.

- R.I - Retrospective Interview.

Citation: Khalaf, B. K., Zin, Z. M., \& Al-Abbas, L. S. (2022). Contemporary perspective on cognitive development: Reconceptualising situational context as embedded model. International Journal of Instruction, 15(1), 401-420. https://doi.org/10.29333/iji.2022.15123a 
- \# - Participant stops speaking.

- - Participant shows hesitation.

\section{INTRODUCTION}

Higher education is not designed to produce graduates who can only work within the restricted framework of solving textbook problems. Graduates should be able to develop cognitive abilities for continuous learning and problem-solving in real-life situations. In most disciplines, a theory is only a simplified form of practice and there is no one answer to solve numerous problems. Therefore, it is essential to understand that university education must develop learners' background knowledge and cognitive skills to facilitate independent life-long learning. Therefore, various learning perspectives have been adopted in numerous learning fields based on the educational demands (Leonard, 2002). However, surveys and investigations in the previous literature revealed a shortage between the learners' proficiencies and the educational systems expectations. Previous studies correlated the shortage to some shortages in the instructional models (Elia and EUATC, 2018; García and Veiga, 2015).

The fruitful literature on translation and instructional models has inspired the current study to investigate and re-evaluate the role of two dominant learning models in translation schools, to identify its efficiency in developing translation cognitive processes. Relatively, the current investigation in the previous literature of translation and functional systematic linguistics acknowledged that situational context could not be considered as an additive or secondary factor into the texts, because it contains many mutual social, physical and instructional factors that affect the process of translation (Halliday, 1999; Lee, Liu and Tsai, 2012). This conceptualisation has led to develop a new embedded model of situational context that extends the classification of Halliday's conceptualisation for situational context. Besides, the developed embedded model aims to overcome the cognitive challenges encountered by translators and parallels with the contemporary instructional models' development. Given the above aim of professional translators' education, the new embedded situational model offers desirable functional learning into translation theoretical context.

\section{Background and Rationale}

Many studies have been devoted to the systematic conceptualisation for the concepts of relevant learning context since the early days of Firth (1968), Jakobson (1966) and Halliday, Ruqaiya and Hasan (1985). The earlier description of the relevant contextual feature that contributes to the classification of context was initially declared by Firth (1968) in which the description was indicated as (a) the relevant features of participants (verbal and non-verbal actions of participation), (b) the relevant objects, and (c) the effects of the verbal actions. However, this description did not provide a clear presentation of how relevance was established in the context. The concept of relevance was remodified by Halliday et al. (1985) who presents the factors of Field, Mode and Tenor, that are supposed to leave a trace in the text. So, Hasan (2009, p. 176) clearly stated that "What is relevant in the context of situation would be illuminated by the 
language of the text". Despite providing the context's parameters, the relationship between these parameters and situational context remains surrounded by some mystery.

Numerous studies in the literature have been carried out since the 1960s on the relevant features of context. The nature of those features and effects were the primary concern of the functional communication approach. Simultaneously, the functional communication of a language implies two criteria of engagement in linguistic acts (Hymes, 1964). Firstly, it should pay attention to the new information embedded in the linguistic forms that require an immediate investigation for the situational context as a proper speech activity. Secondly, functional communication must not consider a linguistic form as a frame of reference, but as a context through investigating its general communicative habits. This aims to ensure that the use of any given communication channel occurs as an aspect of the resources that community members can rely upon (Hymes, 2005). Hence, linguistic materials are highly relevant, and the significance of the logic linguistic methodology in the communicative perspective is evident. Thus, it is communication, rather than linguistics, which must clearly describe the cultural and social frames of reference in language. Table presents the main communication factors of context and their linguistic functions in translation approach.

Table 1

Factors of communication adapted from Jakobson (1966)

\begin{tabular}{lll}
\hline No. & The Factor & Function \\
\hline 1 & Message & Meaning \\
\hline 2 & Code & Metalingual \\
\hline 3 & Context & Referential \\
\hline 4 & Addresser & Emotive \\
\hline 5 & Addressee & Cognitive \\
\hline 6 & Contact & Phatic \\
\hline
\end{tabular}

The concept of message could be the starting point for any form of conception. In this scenario, where one grants two things, the first could be the concept of the message, which means the sharing of (1) Codes that the message is somehow intelligible to, (2) Participants, such as the addressor and the addressee (could be the same individual), (3) Event that is constituted by the transmission of the message, (4) Channel, (5) Context as a defined shape or form to the message, (6) Topic and comment, i.e., saying something about something, meaning that the message concept implies a range of previously given components (Halliday and Matthiessen, 2014). The interest of the sender or addressor regarding the other components encompasses functions such as identifying the source and expressing an attitude toward the event as a whole or towards one or more components, such functions may be conscious, unconscious, intended, or attributed.

Moreover, Wingate, Andon and Cogo (2011) indicated the advantages of implementing embedded approaches due to the development in communities of practice for various faculty programmes. Therefore, the embedded approach represents an ideal opportunity to unify the variety of models' characteristics in different disciplines and educational practices. Thus, the embedded situational context model was developed to fit the necessities in the current research. Furthermore, the embedded situational-context aims 
to enhance knowledge acquisition in long-term memory. The development in translators' cultural background knowledge reflected on their cognitive skills during translation's cognitive process (Baker, 2018). This condition highlights the environmental favourability of relevant situations addressed by Peters, O'Connor and Rudolf (1980) to achieve a context of learning enterprise.

\section{Theoretical Development}

The current study investigated the classical concepts of the systematic functional approach and the previous conceptualisation of Halliday's classification for situational context. Previous studies found Halliday's concepts insufficient to fulfill the linguistic functions of a communicative act of translation (Baker, 2018; Hatim and Mason, 1997; House, 2006; Kovala, 2014). Thus, the inclusion of some functional concepts would integrate with employing the pragmatic and semiotic dimensions of situational context incorporated in developing the communicative functions. The development of situational context classification would facilitate the cognitive process of learning by developing learners' background knowledge and cognitive skills to achieve the communicative function of learning activity in different fields.

Tessmer and Harris (2013) considered the learning environment as a key factor in constructing new models. Thus, the role of learners, educators and learning instructional models must be considered in reconceptualising and designing the new situational context model. Besides, features of effective exchanging roles between the addressor and addressee were considered as the primary notions for the developed model. Thus, the functional concepts of the developed embedded situational model are the message which contains the processing action and what is meant in the communicative act. The second concept is event which refers to the conventional meaning of the act. Third concept is settings of situation which contains the concepts of place and time. Lastly, the channel which refers to how the communication was maintained in a written context and the style used for communication. Figure1 illustrates the implementation of the developed concepts into the systematic functional approach.

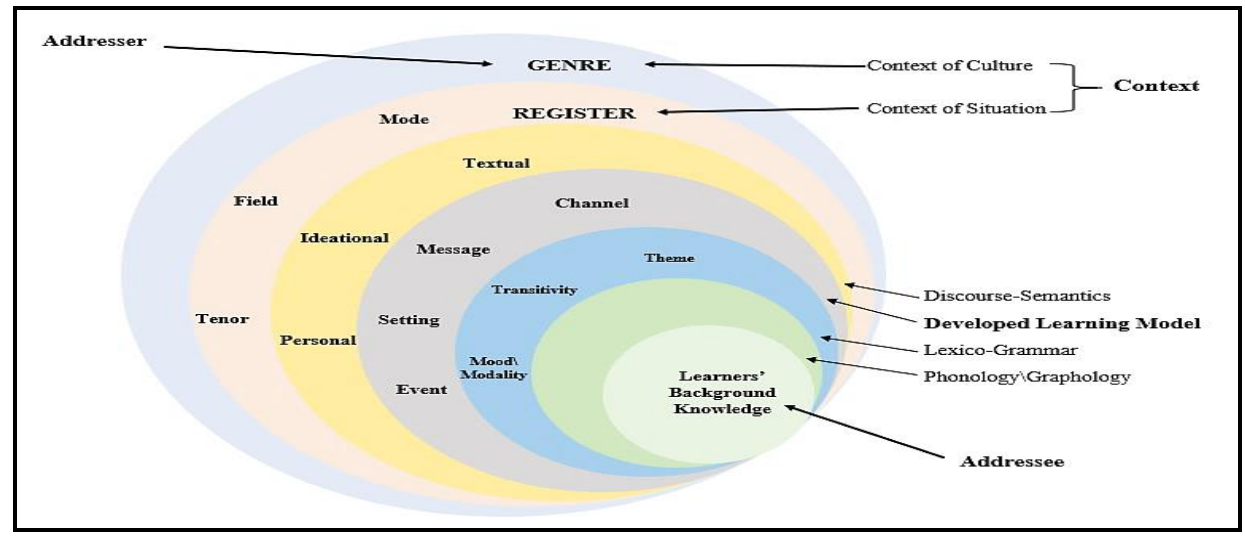

Figure 1

Theoretical implementation of the embedded model into SFL 
The systemic functional interaction between the addressor and the addressee is carried out through the broad context deployed by an addressor and addressee. This interaction aims to facilitate the process of knowledge processing or acquisition starting from the short-term memory until the stage of knowledge storage in the long-term memory to improve the cognitive activity of learners (Brownlee, 2019; Cowan, 2019; Yassuda, Carthery-Goulart, Cecchini, Cassimiro, Fernandes, Baradel, Garcia, Nitrini, Della Sala and Parra, 2019). The developed embedded model motivates the cognition process for better cognitive performance to ensure well information transference between the longterm and short-term memories and avoid interruption of retrieving and implementing background knowledge as shown by Ericsson and Kintsch (1995) and Brownlee (2019). Nevertheless, this process incorporates a mental image of a specific context concerning a particular situation out of the broad related contexts. This cognitive process enhances the learner's background knowledge and implements a higher understanding through contradicting, supporting or building on the previous background knowledge. Figure 02 showed the systemic cognitive process of the interaction between the broad surrounding context and learner's cognition.

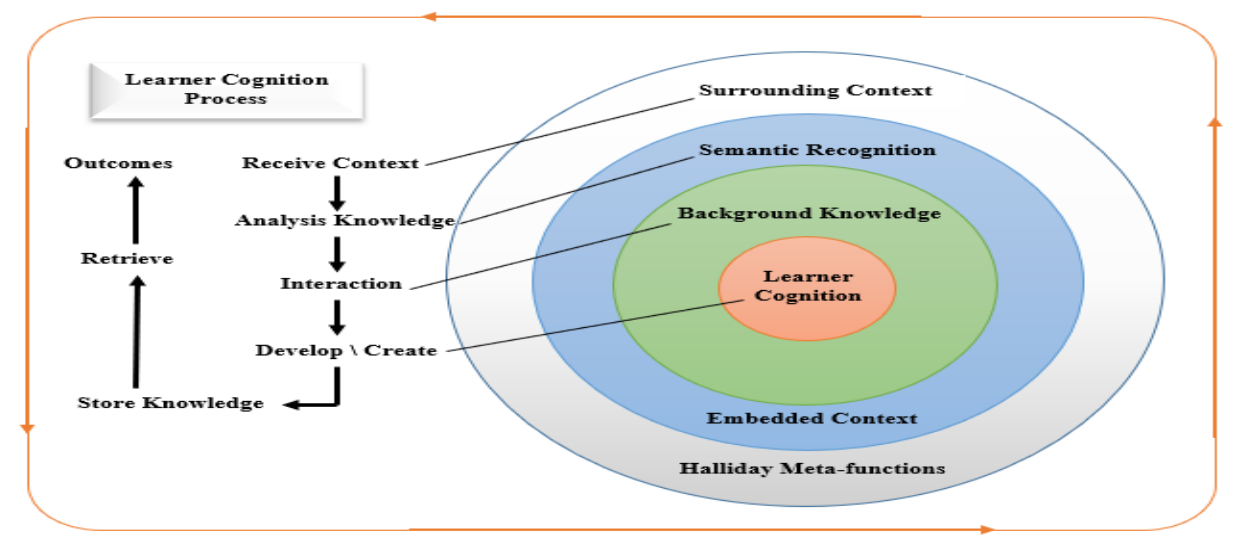

Figure 02

Cognitive processing in practices

The systemic cognitive process of the developed situational context application classifies the cognitive process from a broad context of the genre into smaller segments for the related situation (Newmark, 2004). During the analysis process of acquired knowledge, the text is analysed and understood from the extra-linguistic component of a register that contains the cultural and situational context of expression or sentence to the smaller segments of situational. The interaction between the background knowledge and the developed situational context transforms the text into a more in-depth semantic process of text analysis. This process identified by the correct choice of phonology and graphology in the target text through cognitive functional activities. The semantic and semiotic functions are embedded in the developed context that enables learners to convey the intended function of a text through the vehicle of pragmatic linguistic choices. In conclusion, learners would have trustworthy outcomes, because they 
naturally trust the knowledge generated from practice more than the knowledge they memorize (Slavin and Davis, 2012). This development would contribute to the development of self-confidence in their final cognitive outcomes.

\section{METHOD}

Instruments of data collection are considered as internal parts of the research design (Miles, Huberman and Saldana, 2014). The current research adopted a mixed-methods approach to collect concurrent data on participants' cognitions during cognitive translation activity. The adopted qualitative research instruments are thinking aloud protocols followed by retrospective interviews. However, two translation tasks had been adopted to operate the cognition of the participants during thinking aloud process. The last research instrument was a survey questionnaire on participants' self-confidence. These instruments had been deployed in systematic sequenced sessions during the process of data collection.

\section{Materials}

The first research instrument is thinking aloud which operated by two translation tasks in two sessions. The present research invested in the most challenging texts that required high cognitive processing to be the material of those tasks, which are cultural expressions. The importance of those expressions came from its literary and practical functions in our daily life, for example being used in different genres of literary works, hot news titles, government statements, and commercial advertisements (Honk, 2013; Moosavi, 2000). The context of the present research required further restriction for the typology of those expressions. Due to the cultural background of the research participants, the Iraqi proverbial system had been adopted to fulfill the required material of both translation tasks. Thus, twenty proverbs had been selected randomly, ten metaphoric and ten metonymic, to be the material of two translation tasks in the present study (Appendix A).

The second qualitative instrument is a retrospective interview which consisted of ten open-ended questions following Jacob and Furgerson (2012) modulation of interview protocols. The questions designed to inquire about the challenges and strategies which the participants encountered during the activity of translation. Additionally, it is inquired on the role of translation aids and the embedded situational context during translation activity. In terms of questions' validity, two inter-ratters were appointed to validate the content and structure of the interview's questions to achieve the desired objectives (Appendix B). Finally, self-confidence questionnaire of twenty-four questions was adapted from Baldwin, Ebert-May and Burns (1999) and Jones (2001) models for scaling participants' academic self-confidence in the performed task. The questionnaire was amended according to the design of the current research. The questions were measured through content validity indexing of Polit, Beck and Owen (2007). Four expert inter-ratters involved as panellists to measure the validity of the questions for the present research context. The final form of the questionnaire acquired $91.66 \%$ of content validity by the panellists (Appendix C). In addition, the questionnaire designed to be answered in 5 points scale ranged from $1=$ Not at All Confident to $5=$ Totally Confident according to the performed task. 


\section{Participants}

Many researchers emphasise the importance of the participants' selection stage. Yin (2009) found that screening proper participants for a research reflects a core practice by implementing a set of selection criteria. In this research, a purposive selection process based on the responses in a participants' selection test was carried out in two translation schools. The selection test consisted of a set of questions on translation challenges, strategies and thinking aloud as a research instrument (Appendix D). The previous literature recommended that ten reliable participants are required to participate in thinking aloud experiment to obtain more than $90 \%$ of usability samples (Bevan, Barnum, Cockton, Nielsen, Spool and Wixon, 2003; Bryman, 2016). Accordingly, ten undergraduate students, 22-25 years old, from each translation school are selected to participate in the current research, the first school adopted traditional-based and the second school adopted the inquiry-based model. The participants were cutting the edge of their last semester in their university education.

\section{Data Collection}

The implementation of the present research methods followed a sequence of five stages. Whereas, the first stage was processing of the first thinking aloud session through translating ten proverbs without embedded context. This stage aimed to collect quantitative outcomes of the first translation task and record participants' verbalisations simultaneously. The second stage was assessing the participants' self-confidence on the performed task by deploying pre-self-confidence questionnaire. While, the third stage was the second session of thinking aloud by implementing another set of ten proverbs within an embedded situational context. Similarly, the participants' verbalisations had been recorded for tracking cognitive processing. The fourth stage was the retrospective interview session that took place immediately after the second session of thinking aloud for more in-depth inquires on the cognitive challenges and illustrating complex verbalisations in participants' verbalisations. The last stage was applying the same set of questions as post-questionnaire to investigate participants' self-confidence in performing the second translation task. Time limits had been set up for every stage of data collection, whereas, every thinking aloud session has given 30 minutes, self-confidence questionnaire session 15 minutes and interview session 30 minutes. Finally, the participations carried out individually in one working day for every participant.

\section{Data Analysis}

The first data analysis strategy was preparing raw data in four sequenced steps including protocol transcription, classifying data, assessment of translation outcomes and inserting data into the computer software. After completing the transcriptions of retrospective interviews, further steps had been taken by the researcher to ensure the reliability of the interviews' transcripts. Whereby, the participants reviewed the transcripts for content validity. This member checking procedure maintains the research's trustworthiness on the qualitative interview transcripts (Denzin and Lincoln, 2005). Besides, this step ensures attaining participants' intent in their words and allows correction of factual errors which might happen during the transcription stage. 
After the accomplishment of thinking aloud and interview protocols' transcription and revision, the data were inserted into computer software for further systematic qualitative analysis display. The implementation of transcripts into computer software allows the researcher to organise data, save time, efforts and enhance the quality of data presentation (Flick, 2014). Max QDA.11 was used for the analysis of qualitative data due to its ability to process data in the Arabic language. The software facilitates capturing items, linking ideas together in the transcripts and drawing charts for the final thematic findings. In addition, the current research adopted the thematic analysis model of Clarke and Braun (2013) for analysing thinking aloud and retrospective interviews' protocols in six main steps as shown in Figure .3. This model was used as the primary method to identify, analyses and report patterns or themes within the collected data.

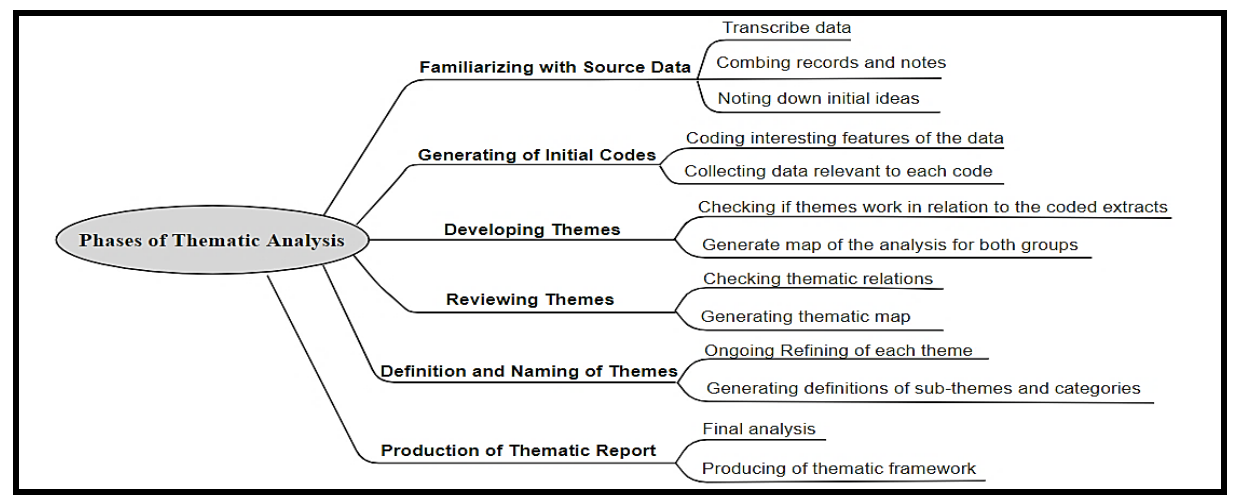

Figure 3

Thematic analytical model

However, the outcomes of both self-confidence questionnaires have been categorised and inserted into computer software to obtain the findings on statistical analysis. Systematic quantitative descriptive analysis, mean score and standard deviation for selfconfidence questionnaires were generated by SPSS.25. While the assessment of both translation tasks outcomes was carried out based on the adopted translation strategies and the equivalence of translations. Table .2 shows the points awarded for participants' translations.

Table 2

Points awarded for translation outcomes

\begin{tabular}{ll}
\hline Points & Strategy \\
\hline 5 & Cultural Equivalence \\
\hline 4 & Neutral Translation \\
\hline 3 & Literal Translation \\
\hline 2 & Paraphrasing \\
\hline 1 & Illustration \\
\hline 0 & Wrong choice \\
\hline
\end{tabular}

Moreover, the final assessment for every translation task ranges from 0-100 points. Table. 3 displays the interpretations of individual outcomes in each translation task. 
Table 3

Assessment of participants' translation outcomes

\begin{tabular}{ll}
\hline Points & Interpretation \\
\hline $0-49$ & Fail \\
\hline $50-70$ & Good \\
\hline $71-89$ & Very Good \\
\hline $90-100$ & Excellent \\
\hline
\end{tabular}

As well, the measurements of self-confidence questionnaires' findings are reflected in the following cut-off points as proposed in the scales by Bagheri and Pihie (2014) and Gilkey, Magnus, Reiter, McRee, Dempsey and Brewer (2014) which display in Table 0

Table 0

Levels and interpretations of self-confidence

\begin{tabular}{ll}
\hline Grades & Interpretations \\
\hline $1-2.13$ & Low confidence \\
\hline $2.14-3.27$ & Moderate confidence \\
\hline $3.28-5.0$ & High confidence \\
\hline
\end{tabular}

\section{FINDINGS}

The thematic qualitative analysis of the study is concluded with designing a thematic framework containing all related themes, sub-themes, categories and coding gathered from participants' transcripts. The thematic framework was used to analyses both transcripts of thinking aloud and retrospective interviews (Ericsson and Simon, 1987; Saldaña, 2016). Additionally, the current thematic framework's design retained the ability to show how systematic inter-relation occurred between themes and related concepts that lead towards the development of target model (Corbin and Strauss, 2014). Hata! Başvuru kaynağı bulunamadı. presents the thematic findings with related themes, sub-themes and categories before the application of the embedded model.

Table 5

Thematic challenges of cognition

\begin{tabular}{rllll}
\hline No. & Sub-Theme & Description & Categories & Code Examples \\
\hline 1. & Meaning & $\begin{array}{l}\text { Participants encounter } \\
\text { challenges to find the } \\
\text { meaning }\end{array}$ & $\begin{array}{l}\text { Vocabulary, } \\
\text { Understand, Wrong, } \\
\text { Assistance, Search. }\end{array}$ & $\begin{array}{l}\text { Did not know, meaning, } \\
\text { means, did not understand, } \\
\text { need assistance, search. }\end{array}$ \\
\hline 2. & $\begin{array}{l}\text { Background } \\
\text { Information }\end{array}$ & $\begin{array}{l}\text { Participants encounter } \\
\text { challenges to remember } \\
\text { meaning or vocabularies }\end{array}$ & $\begin{array}{l}\text { Heard, Know, Level, } \\
\text { Similar, Remember, } \\
\text { Previous study. }\end{array}$ & $\begin{array}{l}\text { Do not heard it before, do } \\
\text { not know about it, I don't } \\
\text { know, I do not know similar } \\
\text { proverb. }\end{array}$ \\
\hline 3. & Experience & $\begin{array}{l}\text { Participants showed } \\
\text { limited cognitive skills }\end{array}$ & Decline, inability. & $\begin{array}{l}\text { limited skills, strategy, } \\
\text { during my study, problem- } \\
\text { solving. }\end{array}$ \\
\hline 4. & Assurance & $\begin{array}{l}\text { Participants' lack of } \\
\text { self-confidences during } \\
\text { translation practice }\end{array}$ & $\begin{array}{l}\text { Probably, Suspicion, } \\
\text { untrust. }\end{array}$ & $\begin{array}{l}\text { Possible, I am not sure, I } \\
\text { must check, I think. }\end{array}$ \\
\hline
\end{tabular}

This framework is developed to analyses the challenges in participants' cognitions in during the first translation task. For example, P.1 stated in TAPs for translating the first 
metaphoric proverb "what does the proverb means, the proverbs are written in the Arabic language, but I do not understand the intended meaning \#". P.7 mentioned in TAPs for translating the third metaphoric proverb "What shall I use from English words (vocabularies) for the Arabic word Khair $\sim$ I will search in the dictionary, Man Subak Galab I did not understand what does it mean, Man Subak Galab \#, Does it a synonymous for the proverb 'Winner who laugh at the end'. What... what... $\underline{\text { I do not }}$ know". While, P.4 in RI "I did not understand some proverbs in the Arabic language because I do not know those proverbs before this time, so I have to guess the intended meaning which may be right or wrong".

Additionally, P.2 mentioned in TAPs for translating the third metaphoric proverb "This proverb I heard it before this time, $\underline{I}$ already know, Al-Khair Eam ... I think I heard it in one of the novels which I read before. But I do not remember $\#, \underline{I \text { have to check the }}$ meaning of the words in the English dictionary $\#$, it does not show any equivalent in the English language". P. 3 mentioned in TAPs for translating the fifth metaphoric proverb "I think that I know this proverb before this time, but I cannot remember it \#, I will translate the meaning of the proverb literally if I will not find any equivalent proverb in English language". P.4 stated in RI "However, I studied cultural texts translations in the third stage of my study, but I cannot remember them". P.7 confirmed this opinion in his RI "The main challenge for me was remembering equivalent proverbs for Arabic proverbs in English language to adopt cultural equivalent as main translation strategy". In contrary, the verbalisations of the participants in the second session of thinking aloud and their comments in the retrospective interviews showed the cognitive development in participants' cognition.

The thematic findings reflected the development of participants' cognitions in the second translation task through the high indications of thematic implications on related classification. The first participant stated in TAPs of the first metaphoric proverb "This proverb means the gentleman, I understand the proverb, I will transfer it into English or find equivalent one". P.2 mentioned in TAPs for translating second metaphoric proverb "I heard this proverb before this time. What is the meaning of this proverb or the message addressed by the embedded context? I remembered it". While, P.10 mentioned in RI "The process of finding accurate meaning for the proverb starts with designing a wide line for the vocabularies' meaning that may be used during the translation. Then, the process of selecting the accurate one starts by filtering according to the relation of each vocabulary's meaning with the current context". P.7 stated in RI "The proverbs embedded within its context of use were easier than the proverbs without the context because it helps a lot in understanding proverbs' meanings".

Whereas, P.8 mentioned in TAPs for translating third metaphoric proverb "I remember, there is an equivalent proverb in Arabic for this one, Mn Jad Wajad". While, P.9 added for translating second metonymic proverb in his TAPs "I remember this proverb refers to the person who interferes in the affairs of others, this proverb has equivalent proverb in Arabic Man Tadakhal Fi Ma La Yaneeh Lake Ma La Eurdeh". P.5 stated in RI "the context helped in the translation process, because I do not know all the proverbs. So, it enhanced my background knowledge and confidence in translating the proverbs". P.4 
added further description on developing his previous knowledge on the proverbs in RI "The written context helped me in understanding the intended meaning of the proverbs and develop my background knowledge around $75 \%$ more than the first task of translating proverbs without context. Also, it added to my knowledge some information about the proverbs which I do not know before". However, the statistical findings of translation tasks reflected similar paralleled findings. Table. 6 displays the outcomes of both groups' participants in the first translation task without situational context.

Table 6

Participants' outcomes in the first translation task

\begin{tabular}{llclcl}
\hline \multirow{2}{*}{ Group } & \multicolumn{2}{l}{ Low Knowledge } & \multicolumn{2}{l}{ High Knowledge } & Average Time \\
& Fail & Good & Very Good & Excellent & \\
\hline Traditional-Based & $40 \%$ & $50 \%$ & $10 \%$ & $0 \%$ & $28.06 \mathrm{~min} . \uparrow$ \\
\hline Inquiry-Based & $30 \%$ & $70 \%$ & $0 \%$ & $0 \%$ & $26.54 \mathrm{~min} . \uparrow$ \\
\hline
\end{tabular}

$* \uparrow=$ More time-ingesting indicates low cognitive skills.

Whereas, the traditional-based group required an average time 28.06 minutes to finish the first translation task. Although, participants had consumed this long time, but they did not review their answers and focused on accomplishing the task. Translation outcomes' assessment showed that traditional participants had 40\% failed, 50\% Good and $10 \%$ very good translation. Accordingly, these findings indicated that traditionalbased participants had low levels of background knowledge and cognitive skills according to the concept of translation quality and time-consuming. The second group of inquiry-based participants showed similar levels of outcomes $30 \%$ fail and $70 \%$ good translations in average of 26.54 minutes. This time consumption and low levels of outcomes reflected high complicated cognitive processing during the first task which displayed low background knowledge and cognitive skills. While, the enhancement in the required time to complete the task displays a higher level of cognitive skills as shown the second translation activity. Table 0.7 shows translation outcomes acquired by both groups in the second task.

Table 07

Participants' outcomes in the second translation task

\begin{tabular}{lccccc}
\hline \multirow{2}{*}{ Group } & \multicolumn{2}{l}{ Low Knowledge } & \multicolumn{2}{l}{ High Knowledge } & Average Time \\
& Fail & Good & Very Good & Excellent & \\
\hline Traditional-Based & $0 \%$ & $0 \%$ & $70 \%$ & $30 \%$ & $15.03 \mathrm{~min} . \downarrow$ \\
\hline Inquiry-Based & $0 \%$ & $0 \%$ & $80 \%$ & $20 \%$ & $14.06 \mathrm{~min} . \downarrow$ \\
\hline
\end{tabular}

$* \downarrow=$ Less time-ingesting indicates high cognitive skills.

Accordingly, traditional-based participants had $70 \%$ very good and $30 \%$ excellent translations. While, inquiry-based group had $80 \%$ very good and $20 \%$ excellent translations. These findings acquired in average time 14.06-15.03, that displayed the cognitive development in participants' cognitions after the implementation of the embedded model. Furthermore, traditional-based participants showed a high level of self-confidence in the second translation task more than the first task, due to the enhancement encountered during the cognitive translation practice as shown in 
Table.8.

Table 8

Results of traditional-based participants' self-confidence

\begin{tabular}{llllll}
\hline & & Mean & No. & Std. Deviation & Std. Error Mean \\
\hline $\begin{array}{l}\text { Traditional } \\
\text { Group }\end{array}$ & $\begin{array}{l}\text { Pre- } \\
\text { Questionnaire }\end{array}$ & 1.8625 & 10 & .34418 & .10884 \\
\cline { 2 - 6 } & $\begin{array}{l}\text { Post- } \\
\text { Questionnaire }\end{array}$ & 3.9458 & 10 & .45814 & .14488 \\
\hline
\end{tabular}

* 1-2.13 Low confidence, 2.14-3.27 Moderate confidence, 3.28-5.0 High confidence.

Relatively, Table.9 displays the results of inquiry-based participants' post-selfconfidences questionnaire, which was higher than the scores in the pre-self-confidence questionnaire. These findings indicate the statistical significance of the developed embedded model for inquiry-based participants by improving their self-confidence during the second translation task's performance. Thus, it could be concluded that the application of embedded situational context was effectively increased inquiry-based participants' self-confidence during the second translation task.

Table 9

Results of inquiry-based participants' self-confidence

\begin{tabular}{llllll}
\hline & & Mean & No. & Std. Deviation & Std. Error Mean \\
\hline \multirow{2}{*}{ GL } & Pre- Questionnaire & 2.1037 & 10 & .27060 & .08557 \\
\cline { 2 - 6 } & Post- Questionnaire & 3.4208 & 10 & .37856 & .11971 \\
\hline
\end{tabular}

* 1-2.13 Low confidence, 2.14-3.27 Moderate confidence, 3.28-5.0 High confidence.

In conclusion, the prent findings of current research can be summerised in comparision to the findings presented in the previous literature since 2002-2020 on the effecency of the contemporary instructional models (Khalaf, 2018; Morrison and Richmond, 2020). Whereas, Table 0.10 illustrates the comparison between previous literature findings and the present research.

Table 00

Cognitive development in comparison to previous literature

\begin{tabular}{lllll}
\hline No. & Description & $\begin{array}{l}\text { Traditional-based } \\
\text { Learning }\end{array}$ & $\begin{array}{l}\text { Inquiry-based } \\
\text { Learning }\end{array}$ & $\begin{array}{l}\text { New Embedded } \\
\text { Situational Model }\end{array}$ \\
\hline 1 & $\begin{array}{l}\text { Background } \\
\text { Knowledge }\end{array}$ & $\begin{array}{l}\text { Limited } \\
\text { knowledge }\end{array}$ & Limited knowledge & High knowledge \\
\hline 2 & Cognitive Skills & Low skills & Moderate skills & High skills \\
\hline 3 & Self-Confidence & Low confidence & $\begin{array}{l}\text { Moderate } \\
\text { confidence }\end{array}$ & High confidence \\
\hline 4 & Motivation & High motivation & Low motivation & High motivation \\
\hline 5 & Performance & Low performance & Low Performance & High performance \\
\hline 6 & Outcomes & Low outcomes & Low outcomes & High outcomes \\
\hline
\end{tabular}




\section{DISCUSSION}

Catford (1965) indicated that any defect in the initial cognitive translation stages would be reflected in the following stages of this process and final outcomes. Therefore, the critical challenges imposed by the analysis stage of translation had extensive impacts on the next stages of this cognitive process. Relatively, the interpreting stage reflected participants limited cognitive skills during the translation activity. These translation skills are related to problem-solving and decision-making. Additionally, the thematic findings reflected in the main theme of skills showed participants' low cognitive skills in solving the major challenges which they encountered during the analysis of source proverbs. Thus, unsequenced processing in the first task between the stages of the translation process and the cognitive skills was clearly shown by the participants during the first task.

In addition, limited cognitive problem-solving skills were incorporated in making the participants took wrong decisions during the first translation activity which supports the findings of Alousque and Negro (2010). Thus, the participants have chosen various incorrect decisions on the adopted translation strategies and selected inaccurate vocabularies to reformulate their target translations. Those procedures affected the entire cognitive process of translation and the quality of translation outcomes in the first task. Consequently, the major challenges in the cognitive process have broad implications on participants' self-confidence during the task. Whereas, participants' verbalisations and comments in the interviews showed that they were not confident about their first task outcomes for numerous reasons. First, they doubted the process of translation, which they were not sure about its accuracy. Second, they were not confident that it reflected the source cultural message or the intended meaning.

However, the second translation task showed that the embedded situational context was able to reflect similar images on the intended meaning of the proverbs. Besides, the situational context interacted with the existing assumptions within participant's cognition in one of three ways; strengthening existing knowledge, contradicting with the existing knowledge or compounding with it (Brown and Rodgers, 2002). The process of interaction between the situational context and the participant's cognition during the second translation task can be displayed in the following Figure 0.4. 


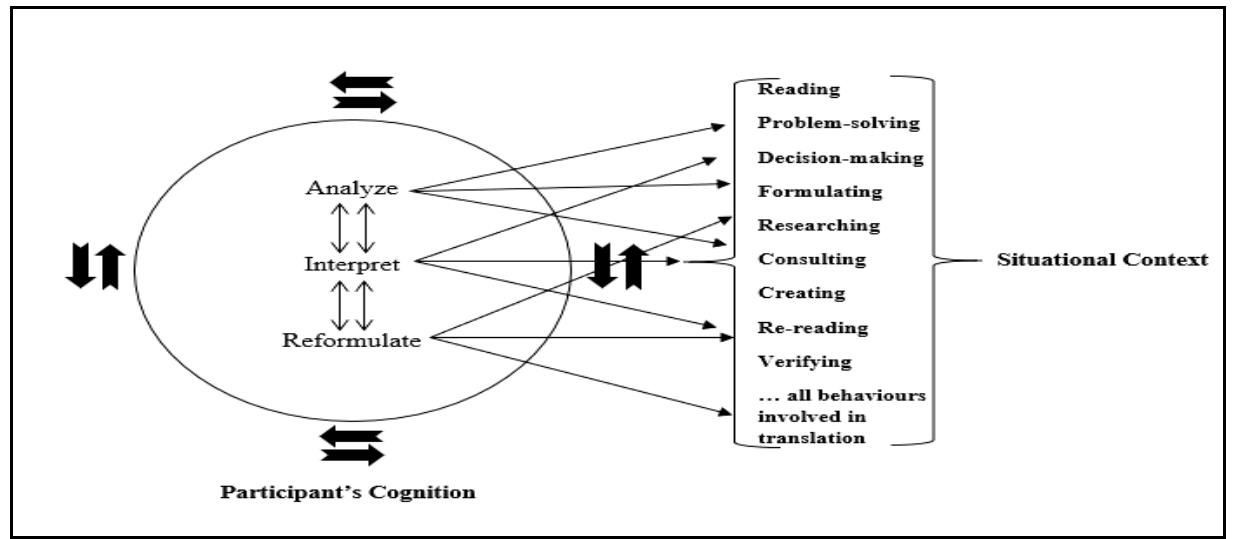

Figure 04

Cognitive processing within the developed embedded context

Likewise, the quantitative findings were built on the previous literature to improve the understanding of the main elements behind those levels of self-confidence in translation practice. The findings showed that pre-self-confidence outcomes for the traditionalbased group were 1.86 M.S and .34 S.D, which is considered as a low level of selfconfidence. Those outcomes are built on the findings of previous literature presented by Gormally et.al (2009), Dorier and Maab (2012) and Lazonder and Harmsen (2016). Additionally, these findings are congruent with the studies conducted by Akkus, Gunel and Hand (2007), María and Luisa (2016) and Mowrer and Klein (2019) on traditional learning approach as a dominant method of learning that require an embedded model which is concerned with developing traditional-based participants' self-confidence.

However, the findings of post-self-confidence questionnaires for the traditional group showed that traditional-based participants had 3.95 M.S and .46 S.D after conducting the second translation task. Those findings are considered as vital signs for high levels of self-confidence more than the outcomes of the pre-self-confidence questionnaire. The new embedded situational context was incorporated in developing traditional-based participants' self-confidence after performing the second translation task. The postquestionnaire findings contradicted with Dorier and Maab (2012), Bunch and Kibler (2015) and many other constructivists view in stating that the traditional-based approach cannot develop learners' self-confidence in comparison to the inquiry-based approach. These findings are aligned with the studies presented by Hussain and Khuddro (2016), Kiraly (2017), Wang, Antonenko, Celepkolu, Jimenez, Fieldman and Fieldman (2019) that developing cognitive background knowledge and skills contribute in developing translators' self-confidences.

Whereas, the post-self-confidence questionnaire showed better outcomes for inquirybased participants in developing their self-confidence in 3.42 M.S and .38 S.D after the second translation task more than the pre-questionnaire. Those findings indicated that inquiry-based participants had high self-confidences in their second translation task outcomes. This result was parallel with the previous literature findings presented by 
Sampson, Grooms and Walker (2011), Furtak, Seidel, Iverson and Briggs (2012) and Lazonder and Harmsen (2016). They indicated that the development in cognitive skills impacted the development of learners' self-confidence at equal levels. However, this finding was inconsistent with the findings of Furtak et al. (2012) and Cherner and Fegely (2017) who supported other instructional approaches and claimed that inquirybased approach is no longer practical in developing learners' cognitive skills and selfconfidence.

In conclusion, the statistical findings in pre- and post-self-confidence questionnaires for both groups had a statistical significance for traditional-based participants .001 , and inquiry-based participants 00.5 . Those grades indicated the efficiency and significance of the developed embedded model in developing participants' self-confidence according to the measurements of Balnaves and Caputi (2001). The statistical significance of the current study reflected the external validity and the study's ability to reflect similar outcomes in a broader context, as indicated by Creswell (2017). This conclusion indicated the usability of a small number of participants in a mixed-method study to reflect these outcomes on a broader context as shown in the previous literature (Alhadreti and Mayhew, 2016; Creswell, 2017; Sova and Nielsen, 2003).

\section{CONCLUSION}

The present work has theoretical importance because the previous literature's argument falls in favour for developing an embedded model of learning to support the contemporary instructional models in developing cognitive processing of knowledge. Besides, there were several necessities behind developing an embedded model for a systematic functional approach which mentioned in the rationale of the study. Accordingly, the current study reconceptualised the communicative function of situational context to be embedded in learning model and empower the functional cognitive engagement in the linguistic activity. Relatively, the review of the previous literature and the outcomes of the first translation task indicated that traditional-based and inquiry-based translators encountered critical and major cognitive challenges during cognitive translation activity. Those challenges related directly to limited background knowledge, low cognitive skills and low self-confidence in the cognitive activity of translation.

In contrast, the second translation task indicated that traditional-based and inquiry-based participants showed higher cognitive progress after the application of the developed embedded model. Those findings offered valuable insights into the systematic process of translation and the cognitive development of the participants to acquire similar impact on future visions of other instructional models and training programmes. Finally, the efficiency of the embedded situational context in developing cognitive translation process can be summarised in three phases. The first phase directed the theoretical development of the embedded model in reconceptualising cognitive translation theory, especially in the enhancement of a systematic functional approach. The second phase reflected the ability of the newly embedded model to fulfil stakeholders' demands for professionalism in translation schools and markets. The third phase shows the usefulness 
of the embedded model in developing cognitive background knowledge of the participants in two different instructional models consistently.

\section{ACKNOWLEDGMENT}

The authors are grateful to the Middle East University, Amman, Jordan for the financial support granted to this research.

\section{REFERENCES}

Akkus, R., Gunel, M., \& Hand, B. (2007). Comparing an inquiry-based approach known as the science writing heuristic to traditional science teaching practices: Are there differences. International Journal of Science Education, 29(14), 1745-1765.

Alousque, \& Negro, I. (2010). Cultural domains: Translation problems. Revista de Lingüística y Lenguas Aplicadas, 4(1), 137-145.

Bagheri, A., \& Pihie, Z. A. L. (2014). Quantitative scales for self-confidences in social sciences. Journal for Educational and Vocational Guidance, 14(3), 255-273.

Baker, M. (2018). In other words: A coursebook on translation (3 rd ed.). New York, USA: Routledge.

Balnaves, M., \& Caputi, P. (2001). Introduction to quantitative research methods: An investigative approach. London: Sage.

Bevan, N., Barnum, C., Cockton, G., Nielsen, J., Spool, J., \& Wixon, D. (2003). The magic number 5: Is it enough for web testing? Paper presented at $\mathrm{CHI}^{\prime} \mathrm{O}$ on Human factors in computing systems. April. Florida, USA.

Brown, J., \& Rodgers, T. S. (2002). Doing second language research (1 st ed.). UK: Oxford Uniersity Press.

Brownlee, J. (2019). Long short-term memory networks with python: Develop sequence prediction models with deep learning (1 st ed.). Australia: Machine Learning Mastery.

Bryman, A. (2016). Social research methods (5 th ed.). Oxford, UK: Oxford university press.

Bunch, G. C., \& Kibler, A. K. (2015). Integrating language, literacy, and academic development: Alternatives to traditional english as a second language and remedial english for language minority students in community colleges. Community College Journal of Research and Practice, 39(1), 20-33.

Cherner, T. S., \& Fegely, A. (2017). Educational apps in the blended learning classroom: Bringing inquiry-based learning into the mix. Current Issues in Emerging eLearning, 4(1), 1-17.

Clarke, V., \& Braun, V. (2013). Teaching thematic analysis: Overcoming challenges and developing strategies for effective learning. The psychologist, 26(2), 120-123. 
Corbin, J., \& Strauss, A. (2014). Basics of qualitative research: Techniques and procedures for developing grounded theory (4 th ed.). London, UK: Sage publications.

Cowan, N. (2019). Short-term memory based on activated long-term memory: A review in response to norris (2017). Psychological Bulletin, 14(8), 822-847.

Creswell, J. (2017). Research design: Quantitative, qualitative, mixed methods, arts based, and community based participatory research approaches (1 st ed.). New York, USA: The Guilford Press.

Denzin, N. K., \& Lincoln, Y. S. (2005). The sage handbook of qualitative research (3 rd ed.). USA: Sage Publication House.

Dorier, J., \& Maab, K. (2012). The primas project: Promoting inquirybased learning (ibl) in mathematics and science education across europe. Retrieved from European Union: www. primasproject. eu/servlet/supportBinaryFiles.

Elia, E. M., \& EUATC, F. (2018). Language industry survey - expectations and concerns of the european language industry. Retrieved from GALA: https://www.galaglobal.org/ondemand/2018.

Ericsson, K. A., \& Kintsch, W. (1995). Long-term working memory (1939-1471). USA: University of Colorado.

Ericsson, K. A., \& Simon, H. A. (1980). Verbal reports as data. Psychological review, 87(3), 215.

Ericsson, K. A., \& Simon, H. A. (1987). Verbal reports on thinking. In C. Faerch \& G. Kasper (eds.), Introspection in second language research (pp. 24-53). USA: Multilingual Matters.

Firth, J. R. (1968). A synopsis of linguistic theory, 1930-1955. Studies in linguistic analysis, 3(2), 168-205.

Flick, U. (2014). An introduction to qualitative research (5 th ed.). London: Sage.

Furtak, E. M., Seidel, T., Iverson, H., \& Briggs, D. C. (2012). Experimental and quasiexperimental studies of inquiry-based science teaching: A meta-analysis. Review of educational research, 82(3), 300-329.

García, M., \& Veiga, M. T. (2015). Guided inquiry and project-based learning in the field of specialised translation: A description of two learning experiences. Perspectives: Studies in Translation Theory and Practice, 23(1), 107-123.

Gee, J. P. (2005). Situated language and learning: A critique of traditional schooling (1 st ed.). New York, USA: Taylor \& Francis.

Gormally, C., Brickman, P., Hallar, B., \& Armstrong, N. (2009). Effects of inquirybased learning on students' science literacy skills and confidence. International Journal for the scholarship of Teaching and Learning, 3(2), 1-22. 
Halliday, M. A. (1999). The notion of "context" in language education. In M. Ghadessy (eds.), Text and context in functional linguistics (pp. 1-24). Amesterdam: John Benjamins Company.

Halliday, M. A. (2009). The gloosy ganoderm: Systemic functional linguistics and translation. Chinese Translators Journal, 1(1), 17-26.

Halliday, M. A. K. (1992). Language theory and translation practice. Rivista Internazionale di tecnica della traduzione, 3(1), 15-25.

Halliday, M. A. K., \& Matthiessen, C. M. (2014). Halliday's introduction to functional grammar (4 th ed.). New York, USA: Routledge.

Halliday, M. A. K., Ruqaiya, H., \& Hasan, R. (1985). Language, text and context. Derkin University Journal, 6(1), 22-39.

Hasan, R. (2009). The place of context in a systemic functional model. In M. A. K. Halliday \& J. Webster (eds.), Continuum companion to systemic functional linguistics (1 st ed., pp. 166-189). London: Continuum International Publishing.

House, J. (2006). Text and context in translation. Journal of pragmatics, 38(3), 338358 .

Hussain, A. E., \& Khuddro, A. (2016). English arabic cultural effect in translation: A relevance theory perspective. International Journal of English Language and Linguistics Research, 4(1), 31-44.

Hymes, D. (1964). Introduction: Toward ethnographies of communication. American anthropologist, 66(6), 1-34.

Hymes, D. (2005). Models of the interaction of language and social life: Toward a descriptive theory. In S. Kiesling \& C. Paulston (eds.), Intercultural discourse and communication: The essential readings (1 st ed., pp. 4-16). Australia: Blackwell Publishing Ltd.

Jacob, S. A., \& Furgerson, S. P. (2012). Writing interview protocols and conducting interviews: Tips for students new to the field of qualitative research. The Qualitative Report, 17(6), 1-10.

Jakobson, R. (1971). Efforts toward a means-ends model of language in interwar continental linguistics (1 st ed.). Amesterdam: John Benjamins Publishing Company.

Jones, H. K. (2001). Academic self-confidence scale: A psychological study in two parts. $\mathrm{PhD}$, University of Tennessee, USA. Retrieved from https://trace.tennessee.edu/utk_chanhonoproj/472

Khalaf, B. K. (2018). Traditional and inquiry-based learning pedagogy: A systematic critical review. International Journal of Instruction, 11(4), 545-564.

Kiraly, D. (2017). Project-based learning: A case for situated translation. Meta: Journal des traducteurs, 50(4), 1098-1111. 
Kovala, U. (2014). Theories of context, theorizing context. Journal of Literary Theory, $8(1), 158-177$.

Kruse, K. (2011). Introduction to instructional design and the addie model (1 st ed.). New York: Sage Publication.

Lazonder, A. W., \& Harmsen, R. (2016). Meta-analysis of inquiry-based learning: Effects of guidance. Review of educational research, 86(3), 681-718.

Lee, C.-Y., Liu, Y.-N., \& Tsai, J.-L. (2012). The time course of contextual effects on visual word recognition. Frontiers in psychology, 3(1), 1-13.

Leonard, D. C. (2002). Learning theories: A to z (1 st ed.). USA: Greenwood Press.

María, R., \& Luisa, R. (2016). A review of the traditional and current language teaching methods. International Journal of Innovation and Research in Educational Sciences, $3(2), 82-88$.

Miles, M. B., Huberman, A. M., \& Saldana, J. (2014). Qualitative data analysis: A methods sourcebook (3 rd ed.). New York: Thousand Oaks.

Morrison, A. B., \& Richmond, L. L. (2020). Offloading items from memory: Individual differences in cognitive offloading in a short-term memory task. Cognitive Research: Principles and Implications, 5(1), 23-37.

Mowrer, R. R., \& Klein, S. B. (2019). A contrast between traditional and contemporary learning theory. In R. R. Mowrer \& S. B. Klein (eds.), Contemporary learning theories: Instrumental conditioning theory and the impact of biological constraints on learning (2 nd ed., pp. 7-19). New York: Routledge.

Newmark, P. (2004). Non-literary in the light of literary translation. The Journal of Specialized Translation, 1(1), 37-41.

Nord, C. (2010). Functionalist approaches. In Y. Gambier \& L. Doorslaer (eds.), Handbook of translation studies (1 st ed., Vol. 1, pp. 120-128). New York: John Benjamins Publishing.

Peters, L. H., O'Connor, E. J., \& Rudolf, C. J. (1980). The behavioral and affective consequences of performance-relevant situational variables. Organizational Behavior and Human Performance, 25(1), 79-96.

Polit, D. F., Beck, C. T., \& Owen, S. V. (2007). Is the cvi an acceptable indicator of content validity? Appraisal and recommendations. Research in nursing \& health, 30(4), 459-467.

Saldaña, J. (2016). The coding manual for qualitative researchers (3 ed ed.). New York, USA: Sage.

Sampson, V., Grooms, J., \& Walker, J. P. (2011). Argument-driven inquiry as a way to help students learn how to participate in scientific argumentation and craft written arguments: An exploratory study. Science Education, 95(2), 217-257. 
Slavin, R. E., \& Davis, N. (2012). Educational psychology: Theory and practice (5 th ed.). Boston: Allyn \& Bacon.

Sova, D. H., \& Nielsen, J. (2003). 234 tips and tricks for recruiting users as participants in usability studies. Retrieved from California, USA: https://www.nngroup.com/reports/how-to-recruit-participants.

Taylor, G., \& Ussher, J. (2001). Making sense of s\&m: A discourse analytic account. Sexualities, 4(3), 293-314.

Tessmer, M., \& Harris, D. (2013). Analysing the instructional setting: Environmental analysis (1 st ed.). London: Kogan Page Publication.

Tiruneh, D. T., De Cock, M., \& Elen, J. (2018). Designing learning environments for critical thinking: Examining effective instructional approaches. International journal of science and mathematics education, 16(6), 1065-1089.

Virtanen, A., \& Tynjälä, P. (2019). Factors explaining the learning of generic skills: A study of university students' experiences. Teaching in Higher Education, 24(7), 880894.

Wang, J., Antonenko, P., Celepkolu, M., Jimenez, Y., Fieldman, E., \& Fieldman, A. (2019). Exploring relationships between eye tracking and traditional usability testing data. International Journal of Human-Computer Interaction, 35(6), 483-494.

Wingate, U., Andon, N., \& Cogo, A. (2011). Embedding academic writing instruction into subject teaching: A case study. Active Learning in Higher Education, 12(1), 69-81.

Yassuda, M. S., Carthery-Goulart, M. T., Cecchini, M. A., Cassimiro, L., Fernandes, K. D., Baradel, R. R., Parra, M. A. (2019). Free recall of bound information held in shortterm memory is unimpaired by age and education. Archives of Clinical Neuropsychology, 35(2), 165-175.

Yin, R. K. (2009). Case study research: Design and methods (5 th ed.). New York: Sage Publication. 